\title{
Viabilidade da recuperação e avaliação de uma edificação residencial para venda no município de Boa Ventura de São Roque - PR
}

\author{
A. S. De Souza ${ }^{1}$, B. P. Dala $\operatorname{Costa}^{1}$, A. Frare ${ }^{1 *}$ \\ *Autor de Contato: frareandreza@gmail.com \\ ${ }^{1}$ Departemento de Engenharia Civil, Centro Universitário Campo Real, Guarapuava, Brasil
}

\begin{abstract}
RESUMO
Com o passar do tempo surgem algumas patologias em imóveis e podem ocorrer falhas, que acabam por gerar vícios e problemas construtivos. O presente trabalho consiste na realização de uma análise da viabilidade de recuperação de um imóvel no município de Boa Ventura de São Roque/PR para valorização no mercado imobiliário. Uma pesquisa de mercado foi realizada a fim de fornecer dados para avaliação do mesmo. Preços de vendas, áreas dos imóveis e padrões de acabamento. Após o levantamento patológico do imóvel realizou-se um orçamendo afim de verificar a viabilidade de reforma antes da venda.
\end{abstract}

Palavras-chave: Patologia, Avaliação, Recuperação, Construção Civil. 


\begin{abstract}
Over time, some pathologies in real estate arise and failures can occur, which end up generating addictions and construction problems. The present work consists of an analysis of the feasibility of recovering a property in the municipality of Boa Ventura de São Roque / PR for valuation in the real estate market. A market research was carried out in order to provide data for its evaluation. Sales prices, real estate areas and finishing standards. After the pathology survey of the property where causes were found and how to solve them, a budget was made to see the cost and feasibility of reform before the sale.
\end{abstract}

Key words: Pathology, Evaluation, Recovery, Civil Construction.

\title{
RESUMEN
}

Con el tiempo, surgen algunas patologías en el sector inmobiliario y pueden producirse fallos, que acaban generando adicciones y problemas de construcción. El presente trabajo consiste en un análisis de la viabilidad de recuperar una propiedad en el municipio de Boa Ventura de São Roque / PR para su valoración en el mercado inmobiliario. Se realizó una investigación de mercado con el fin de aportar datos para su evaluación. Precios de venta, áreas inmobiliarias y estándares de acabado. Luego del relevamiento patológico del inmueble donde se encontraron las causas y cómo solucionarlas, se realizó un presupuesto para ver el costo y la viabilidad de la reforma antes de la venta.

Palabras clave: Patología, Evaluación, Recuperación, Construcción Civil. 


\section{INTRODUÇÃO}

As patologias na construção não acontecem por acaso, existem diversos fatores que contribuem para isso, erros no dimensionamento, falta de planejamento na execução, materiais mal utilizados e especificados, falta de capacitação profissional.

A análise das patologias são funções também de dois aspectos essenciais, tempo e condições de exposição, o que a torna associada aos conceitos de durabilidade, vida útil e desempenho (LEÃO, 2012). Quando se trata de imóveis, este nicho de mercado denomina-se "Avaliação de Imóveis". Esta avaliação consiste em levantamento de informações e fatores que determinem um preço para o imóvel em questão (FRONZA, 2012).

Conforme Leão (2012), a resistência e a durabilidade de uma edificação dependerá dos cuidados que se tenha com ela e não somente na hora da elaboração do projeto mas também durante sua construção e posteriormente sua manutenção.

Para Zuchetti (2015), com o passar do tempo vão surgindo algumas patologias no imóvel, causadas na maioria das vezes por erros na execução do projeto por profissionais não capacitados.

Segundo Oliveira (2013) quando se pensa em construção civil só vem a mente a fase da obra, porém é somente depois dessa fase que os problemas começam a aparecer e para resolver esses problemas deve - se fazer uma vistoria no imóvel, fazendo o levantamento das patologias, suas causas e como resolver para assim poder também avaliar o imóvel e sua valorização no mercado após a reforma.

O objetivo desse projeto é encontrar maneiras de solucionar os problemas causados por patologias no imóvel localizado no município de Boa Ventura de São Roque, encontrando maneiras corretas para que assim seja feita uma melhoria no ambiente, realizando levantamentos e pesquisas para saber a melhor forma da recuperação do imóvel para assim poder melhorar também o seu valor no mercado.

\section{PROCEDIMIENTO}

\subsection{Considerações sobre o mercado e região}

Considerando que a cidade de Boa Ventura de São Roque é uma cidade pequena com uma população de aproximadamente 6.000 (seis mil) habitantes com poucos imóveis para venda foi utilizado informações de cidades vizinhas onde o mercado imobiliário é maior e tem crescido muito no decorrer dos anos. A região local possui um relevo plano e montanhoso em alguns locais.

\subsection{Caracterização do imóvel}

Uma parte construção do imóvel foi realizada em pré-moldado seguida de chapisco, emboço e reboco sendo $76,00 \mathrm{~m}^{2}$ da mesma onde se tem: cozinha, sala de jantar, três quartos e banheiro a outra parte da construção onde a mesma foi ampliada a fundação foi dimensionada para ser de estacas pré-moldadas de concreto, sendo constituídas de concreto armado; as colunas, as vigas, também foram construídas de concreto armado, com acabamento de tintas acrílicas; a alvenaria estrutural é constituída de tijolos cerâmicos, seguida do chapisco, emboço e reboco, para o acabamento foi utilizado massa corrida e tintas acrílicas. Todas as esquadrias existentes da edificação são de madeira, exceto a porta da entrada da garagem que a esquadria é de ferro; todas 
as janelas de correr com vidro temperado e esquadrias de alumínio sendo que nas duas janelas existentes na sala de estar possuem pingadeira de mármore. Os pisos foram construídos primeiramente com o contra piso, e são todos em cerâmica, o forro é de PVC. A cobertura da edificação em de telhado aparente, com tesouras de madeiras e telhas onduladas de fibrocimento $5 \mathrm{~mm}(244 \times 110 \mathrm{~cm})$. Os banheiros e a cozinha foram feitos com acabamento cerâmico nas paredes de alvenaria. O imóvel possui muro em alvenaria estrutural constituída de blocos cerâmicos, seguida do chapisco, emboço e reboco e grades de ferro em frente e na lateral direita. A Figura 1, nos mostra a parte externa do imóvel.

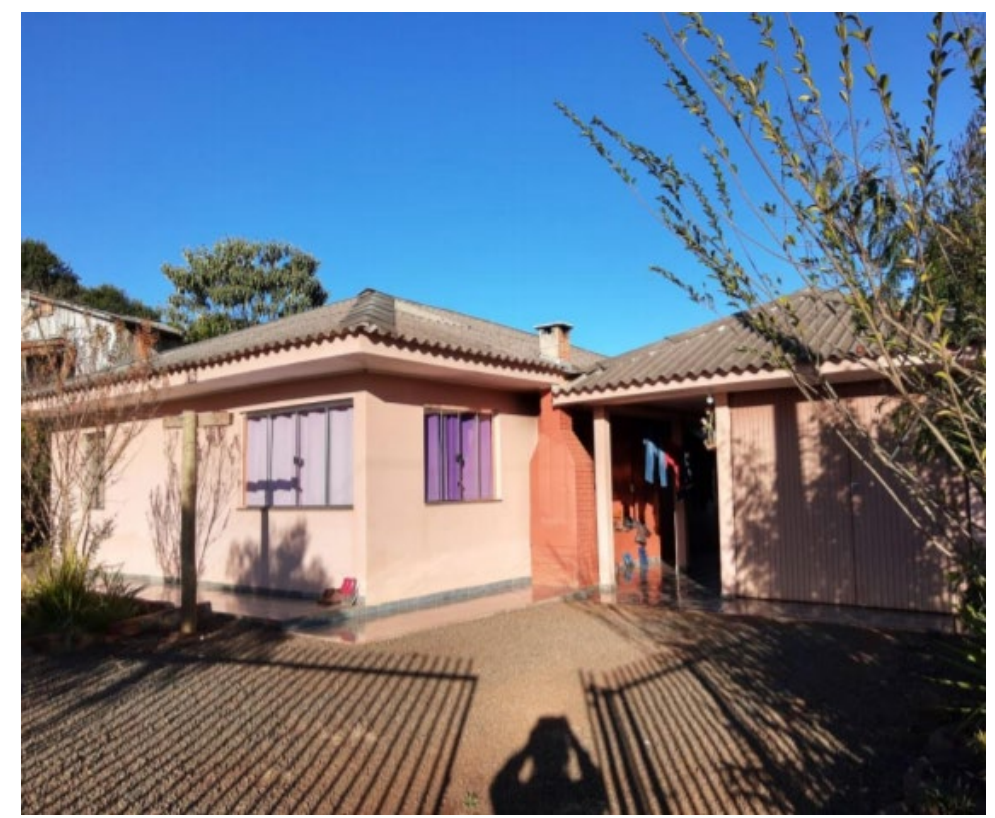

Figura 1. Fachada do ìmóvel

\subsection{Levantamento patológico}

Para obter um diagnóstico correto das manifestações patológicas, realizou-se uma inspeção visual e registros fotográficos do imóvel identificando sua localização e intensidade.

\subsection{Orçamento para reforma}

Para fazer o levantamento de custos da correção das patologias foi necessário realizar uma pesquisa no mercado local.

Para isso buscou-se fazer três cotações, e a partir do valor médio estimou-se o valor dos insumos necessário e da mão de obra para a reforma.

\subsection{Avaliação de valor de mercado do imóvel}

Para avaliar o imóvel em questão foi realizada uma pesquisa de imóveis na região onde foram levantados dados da cidade de Boa Ventura de São Roque e da cidade de Pitanga.

$\mathrm{Na}$ pesquisa efetuada no mercado local foram obtidos 25 (vinte e cinco) elementos dos quais todos foram aproveitados, relativos a ofertas efetivas de imóveis residenciais na cidade de Boa Ventura de São Roque e Pitanga, comtemplados no período de Novembro de 2020.

As variáveis analisadas foram as seguintes: endereço, área privativa, área do terreno, numero de banheiro e dormitórios, vagas de garagem, distancia até o ponto central, padrão de acabamento, 
onde foi utilizado 1 para acabamento em madeira, 2 para acabamento em cerâmica e forro PVC e 3 para acabamento em porcelanato e laje, conservação, onde foi utilizado 0 para conservação regular, 1 para conservação boa e 2 para conservação nova, cidade onde foi considerado 6,36 para população de Boa Ventura de São Roque e 29,99 para população de Pitanga e valor unitário.

\section{RESULTADOS E DISCUSSÕES}

\subsection{Catalogação das patologias encontradas}

Neste item está retratado primeiramente o levantamento de manifestações patológicas identificadas na obra estudada e por consequência as suas possíveis causas.

- Trinca e fissura de revestimento Figura 2. na área externa (a) e área interna (b) e (c) que pode ter sido ocasionado por problemas estruturais relacionados a fundação mal calculada ou até mesmo por falta de mão de obra qualificada. Para sua correção será necessário abrir a fissura com a espátula em formato $\mathrm{V}$, removendo as partículas que estão soltas na parte interna da trinca e aplicar um repara trinca vedante nas aberturas maiores e selante acrílico nas aberturas menores.

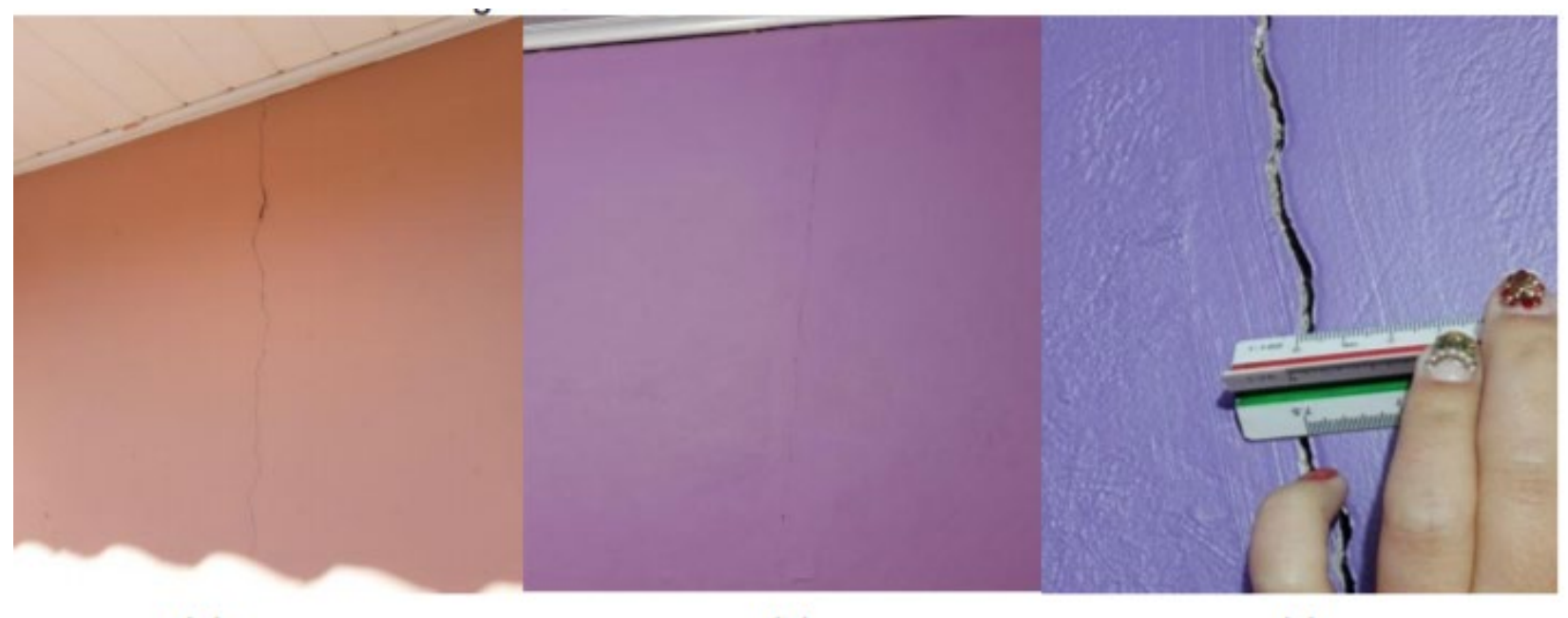

(a)

(b)

(c)

Figura 2. Trinca e fissura de revestimento

Fissuração em parede de alvenaria na região dos pontos de fixação de portas Figura 3. (a), (b) e (c) que pode ter sido ocasionado por falta de vergas e contravergas ou até mesmo por erro na execução das esquadrias. Para fazer sua correção será necessário cobrir a fissura com selante acrílico e fazer acabamento em seguida. 


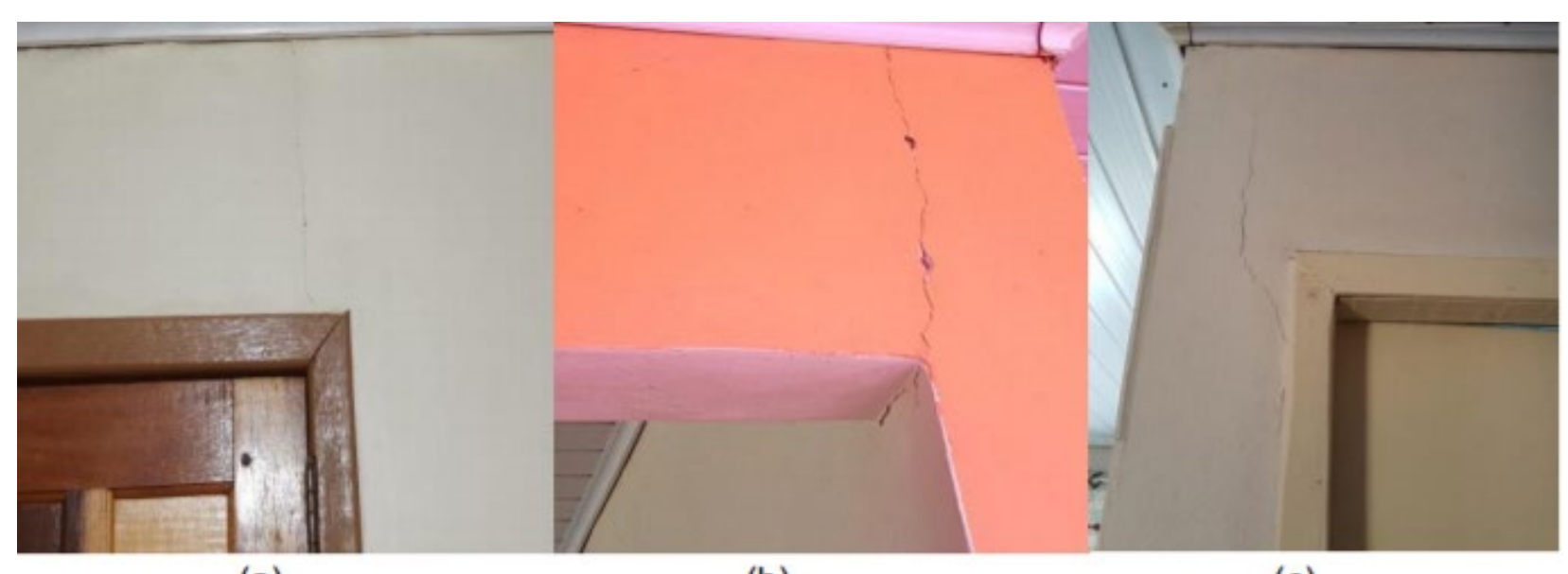

(a)

(b)

(c)

Figura 3. Fissuração em parede de alvenaria na região dos pontos de fixação de portas.

Fissuração em parede de alvenaria na região dos pontos de fixação de janelas Figura 4. (a) e (b), que pode ter sido ocasionado por falta de vergas e contravergas ou até mesmo por erro na execução das esquadrias. Para sua correção será necessário será necessário cobrir a fissura com selante acrílico e fazer acabamento em seguida.

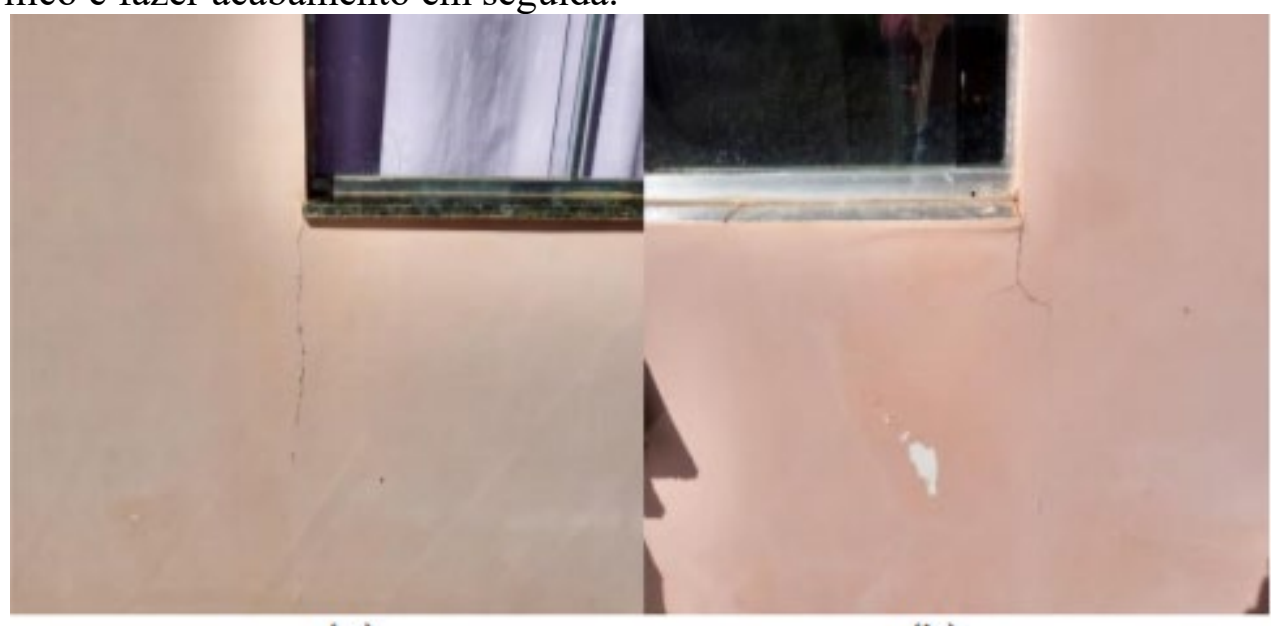

(a)

(b)

Figura 4. Fissuração em parede de alvenaria na região dos pontos de fixação de janelas

Fissuração em parede de alvenaria na região dos pontos de fixação de janelas Figura 5. (a) e (b), que pode ter sido ocasionado nesse caso por recalque na fundação sendo necessário refazer toda a esquadria da janela. Para sua correção será necessário refazer toda a esquadria da janela. 


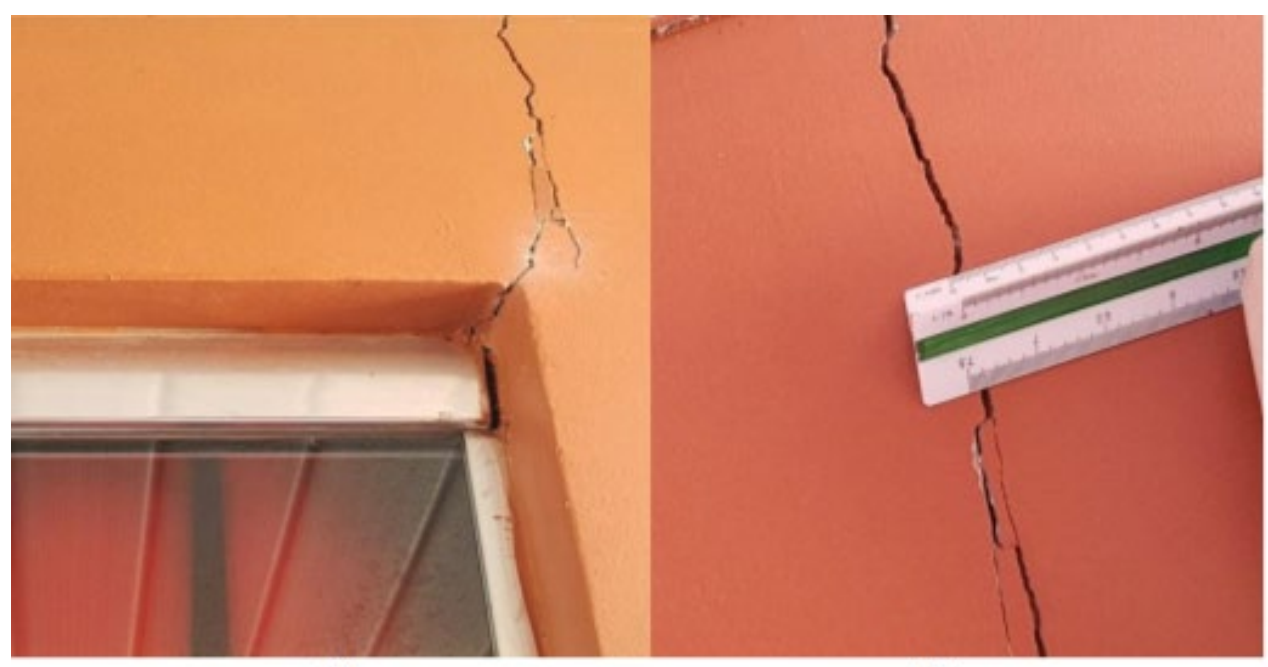

(a)

(b)

Figura 5. Fissuração em parede de alvenaria na região dos pontos de fixação de janelas

Trincas em parede de alvenaria localizada na cozinha, Figura 6 que pode ter sido ocasionado por má aplicação do reboco ou com traço errado, por problemas estruturais ou até mesmo pela variação térmica tendo em vista que a um fogão a lenha no local. Para sua correção será necessário aplicar um repara trinca vedante para fechar a trinca e em seguida fazer o acabamento.

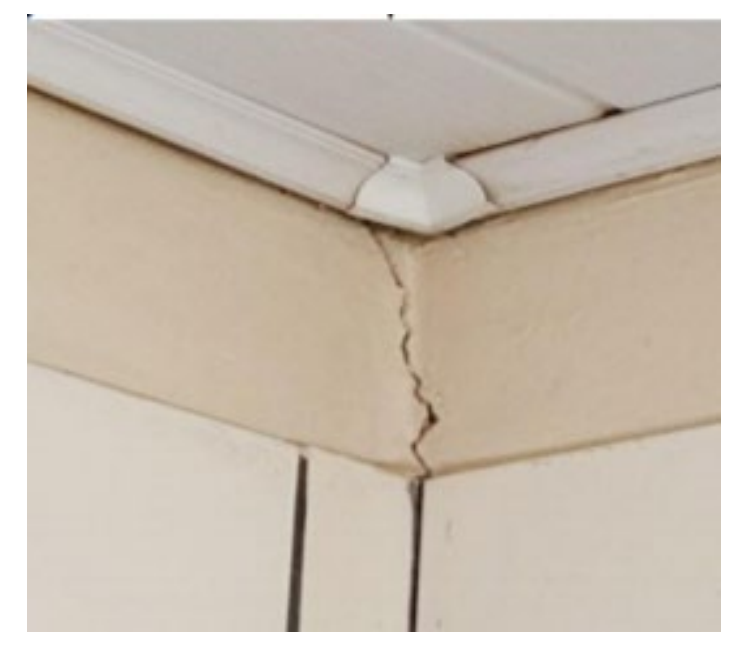

Figura 6. Trincas em parede de alvenaria

Mofo e pintura danificada Figura 7: (a), (b) e (c) causado devido ao excesso de umidade no local. Para sua correção será necessário descartar todo revestimento e refazê-lo com aplicação prévia de produtos impermeabilizantes misturados à massa em seguida refazer a pintura. 


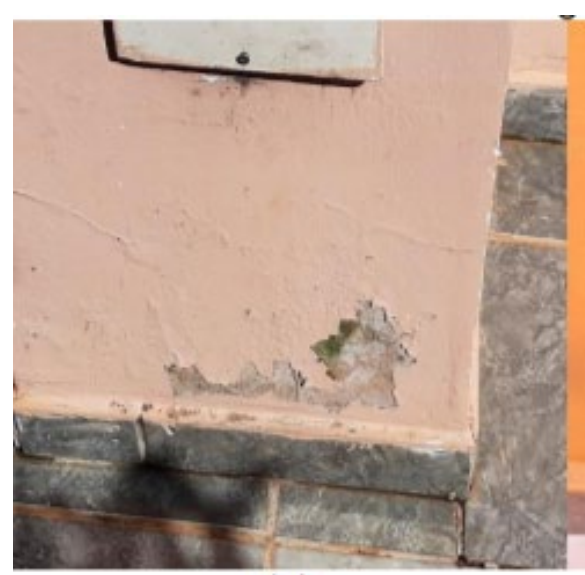

(a) (b)

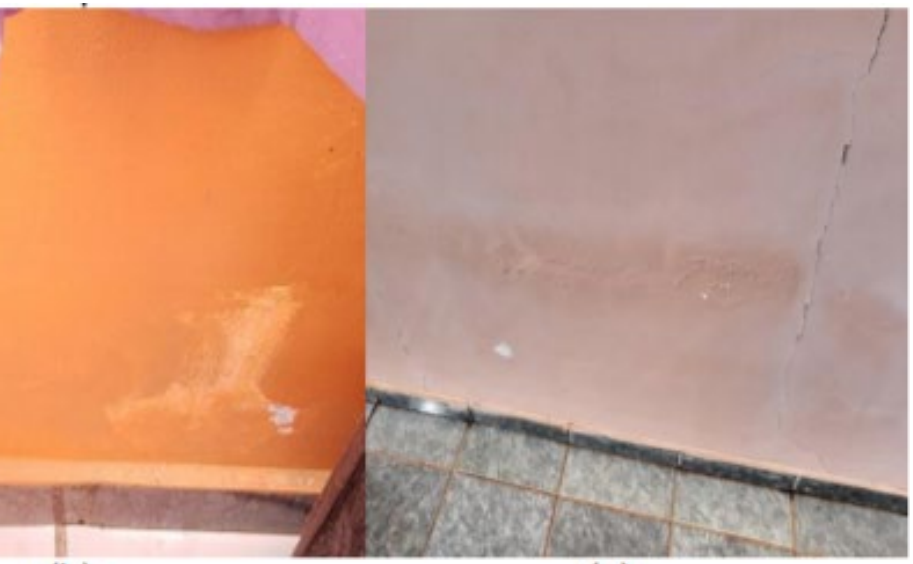

(c)

Figura 7. Mofo e pintura danificada

Trincas verticais em vigas cinta Figura 8 nesse caso ocasionados por excesso de calor devido ter uma churrasqueira no local e também pode ter ocorrido problemas estruturais relacionados a fundação mal calculada ou até dimensionamento errado das armaduras. Para sua correção será necessário descartar todo revestimento e refazê-lo com aplicação prévia de produtos impermeabilizantes misturados à massa em seguida refazer a pintura.

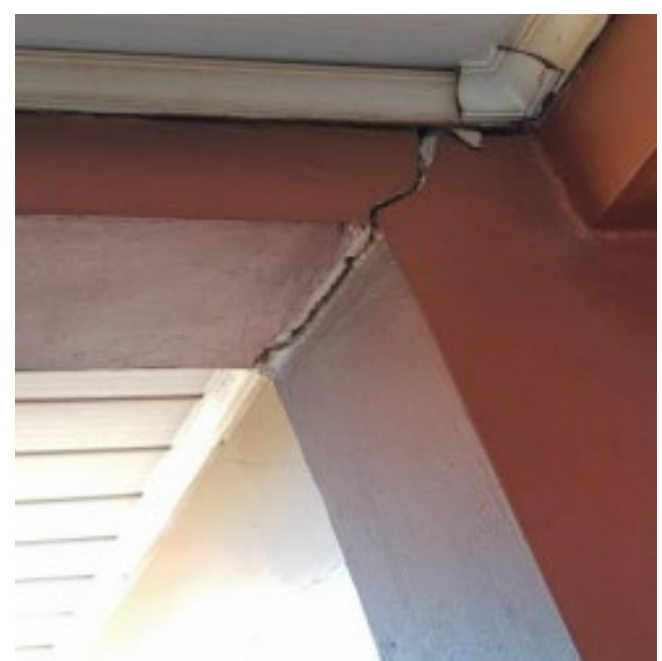

Figura 8. Trincas verticais em viga cinta

\subsection{Custo de reforma}

Através do levantamento de mercado na região obteve-se os custos de reforma para a edificação em estudo. $\mathrm{O}$ valores estão apresentados na Tabela 1.

Tabela 1. Orçamento de reforma

\begin{tabular}{|l|l|l|l|l|l|l|}
\hline Item & Referência & Material & Un & Qtd. & $\begin{array}{l}\text { Valor } \\
\text { Unitário } \\
(\mathrm{R} \$)\end{array}$ & $\begin{array}{l}\text { Valor Total } \\
(\mathrm{R} \$)\end{array}$ \\
\hline 1 & Cotação & $\begin{array}{l}\text { Reparador de trinca Quartozolit } \\
1,5 \mathrm{~kg}\end{array}$ & Un & 3 & 71,90 & 215,70 \\
\hline 2 & Cotação & Selador acrílico Coral 181 & Un & 4 & 90,00 & 360,00 \\
\hline 3 & Cotação & Tinta Acrílica Suvinil & Un & 16 & 90,00 & $1.440,00$ \\
\hline
\end{tabular}




\begin{tabular}{|l|l|l|l|l|l|l|}
\hline & & Semibrilho 2 de mãos 3,6 1 & & & & \\
\hline 4 & Cotação & Massa corrida Suvinil 281 & Un & 4 & 46,90 & 187,60 \\
\hline 5 & Cotação & Mão de obra & Un & - & - & $10.000,00$ \\
\hline
\end{tabular}

\subsection{Valor de mercado do imóvel}

Após a coleta de dados referente as variáveis em estudo: endereço, área privativa, área do terreno, numero de banheiro e dormitórios, vagas de garagem, distancia até o ponto central, padrão de acabamento, onde foi utilizado 1 para acabamento em madeira, 2 para acabamento em cerâmica e forro PVC e 3 para acabamento em porcelanato e laje, conservação, onde foi utilizado 0 para conservação regular, 1 para conservação boa e 2 para conservação nova, cidade onde foi considerado 6,36 para população de Boa Ventura de São Roque e 29,99 para população de Pitanga e valor unitário.

Após o tratamento de dados, a equação de regressão obtida é:

\section{$\mathrm{VU}=1$ / ( 0,001091881 +7,6590946e-07 * Áreaprivativa +-4,2951527e-07 * Área doterreno +-0,016750061*1/Distancia +-0,0001300878* Padrão+-6,1497985e-05 *Conservação +- 4,9638306e-06 * Cidade )}

Onde, para determinar o valor do imóvel antes da manutenção e correção das patologias, os seguintes dados foram considerados: Área privativa: 120,00 $\mathrm{m}^{2}$; Área do terreno: $452,50 \mathrm{~m}^{2}$ Distancia: 2.500,00m; Padrão: 2,00 (normal); Conservação: 0,00 (regular); Cidade: 6,36 (Boa Ventura de São Roque). O resultado do campo de arbítrio segue na Tabela 2.

Tabela 2. Resultado de campo arbítrio

\begin{tabular}{|c|c|c|c|}
\hline & Unitário $\left(\mathrm{R} \$ / \mathrm{m}^{2}\right)$ & Total $(\mathrm{R} \$)$ & Amplitude \\
\hline Mínimo & $1.230,12$ & $147.614,40$ & $-15 \%$ \\
\hline Calculado & $1.447,20$ & $173.664,00$ & - \\
\hline Máximo & $1.664,28$ & $199.713,60$ & $+15 \%$ \\
\hline \multicolumn{4}{|c|}{ Valor adotado: R\$ 164.980,80 } \\
\hline
\end{tabular}

Foi adotado para o imóvel avaliando o valor de R\$ 165.00,00, ou seja, 5\% abaixo do Valor Médio Arbitrado pelo Modelo de Regressão Linear, devido a falta de elementos amostrais transacionados pelo mercado imobiliário, não possuindo amostras de Transação no modelo estatístico. $\mathrm{O}$ valor foi arredondado pois a norma permite arredondamento de até $1 \%$. A equação de regressão para determinar o valor do imóvel após a correção é a mesma, alterando somente a conservação do imóvel, onde as seguintes informações foram considerados: Área privativa:

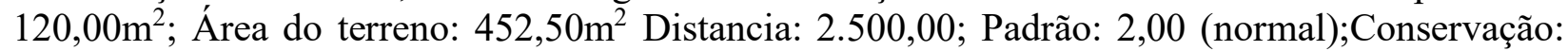
1,00 (boa);Cidade: 6,36 (Boa Ventura de São Roque. O resultado do campo de arbítrio, segue na Tabela 3.

Tabela 3. Resultado de campo arbítrio

\begin{tabular}{|c|c|c|c|}
\hline & Unitário $\left(\mathrm{R} \$ / \mathrm{m}^{2}\right)$ & Total $(\mathrm{R} \$)$ & Amplitude \\
\hline Mínimo & $1.350,30$ & $162.036,00$ & $-15 \%$ \\
\hline Calculado & $1.588,59$ & $190.630,80$ & - \\
\hline Máximo & $1.826,88$ & $219.225,60$ & $+15 \%$ \\
\hline \multicolumn{4}{|c|}{ Valor adotado: R\$ 181.099,20 } \\
\hline
\end{tabular}


Após levantamento identificou-se que corrigir as patologias e posteriormente fazer a reforma da residência para avalia - la para venda. Com ese procedimento pode-se perceber que o imóvel tem uma valorização de aproximadamente $10 \%$, com um valor de venda inicial em $\mathrm{R} \$$ 168.000,00 considerando uma conservação regular, sendo depois de todas as uma avaliação de $\mathrm{R} \$ 181.000,00$, vindo a compensar uma reforma, gastando-se aproximadamente $\mathrm{R} \$ 12.200,00$. A Figura 9 mostra a conservação a conservação do imóvel avaliado e o aumento do valor por $\mathrm{m}^{2}$.

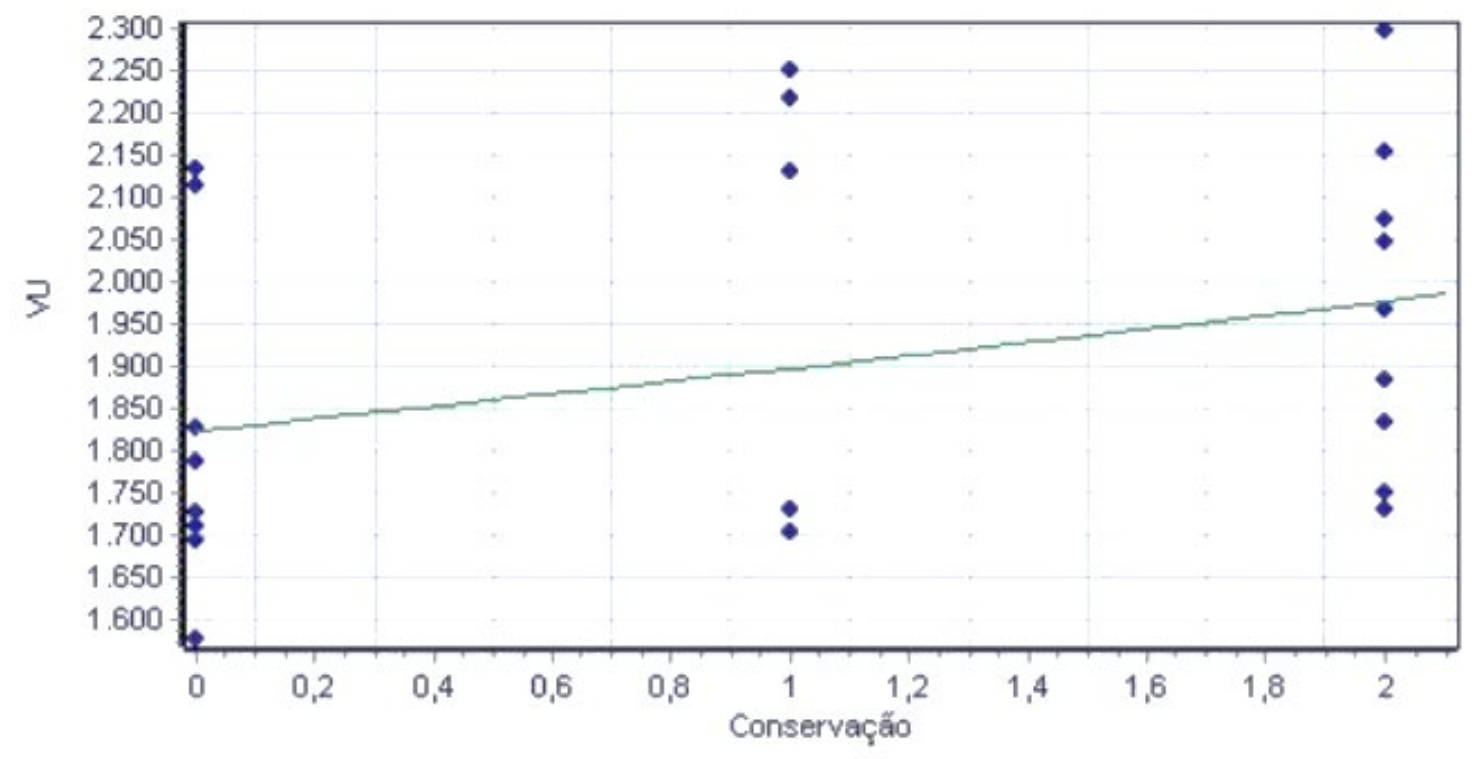

Figura 9. Gráfico de conservação do imóvel avaliado.

Analisando a Figura 9 nota - se que de $\mathrm{R} \$ 1.800,00 \mathrm{o} \mathrm{m}^{2}$ subiu para $\mathrm{R} \$ 1.980,00 \mathrm{o} \mathrm{m}^{2}$ tendo um aumento de aproximadamente $10 \%$ em sua conservação, o que indica uma reforma como uma boa alternativa de valorização do imóvel antes da venda.

\section{Considerações finais}

Esse trabalho foi realizado para a analizar a viabilidade da reforma de um imóvel para venda no município de Boa Ventura de São Roque - PR.

Trouxe em seu escopo o levantamento de patologias encontradas no imóvel a fim de encontrar formas para fazer a correção das mesmas e também o estudo do mercado imobiliário na região.

Observa-se que mesmo tratando-se de uma cidade com poucos dados imobiliários é possível realizar uma avalição da edificação, estimando seu valor.

A pesar da edificação apresentar diversas patologías, as mesmas podem ser fácilmente recuperadas.

Pode-se perceber que a reforma da residência estudada melhora o seu valor no mercado, tendo assim um ganho estimado em $10 \%$.

Concluímos que o estudo de valor de mercado de um bem não é uma mera especulação, é um estudo serio e de grande importância para poder chegar a um valor de mercado mais preciso.

Ressalta-se que para cada caso é necessário realizar-se uma avaliação afim de comprovar a viabilidade. 


\section{REFERENCIAS}

ABNT, Associação Brasileira de normas Técnicas. NBR 14653:2004 - Norma Brasileira de avaliação de Bens, Acessado em 21 de Novembro de 2020.

ANDRADE, E. B. B. Principais Manifestações Patológicas Encontradas em Edificações. Publicado em Brasil escola. Nov/2016. Acesso em: Novembro de 2020.

BRITO, T. F. Análise de Manifestações Patológicas na Construção Civil pelo Método Gut: Estudo de Caso em uma Instituição Pública de Ensino Superior. 79f. Trabalho de Conclusão de Curso de Engenharia Civil, UFP/centro de Tecnologia, João Pessoa, 2017.

CBIC, Câmara Brasileira da Indústria da Construção. Desempenho de edificações habitacionais: Guia orientativo para atendimento à norma ABNT NBR 15575/2013. 2 ed. Brasília, Gadioli Cipolla Comunicação, 2013.

FRONZA, C. M. A Avaliação de Imóveis Residenciais Urbanos na Engenharia: Método Comparativo Direto de Dados do Mercado. Publicado por Revista Técnico - Científica do CREA-PR. $10^{\circ}$ edição. Londrina. Maio/2012.

GONÇALVES, E. A. B. Estudo de Patologias e suas Causas nas Estruturas de Concreto Armado de Obras de Edificações. 174f. Projeto de Graduação do Curso de Engenharia Civil. Rio de janeiro. 2015.

IANTAS, L. C. Estudo de Caso: Análies de Patologias Estruturais em Edificação de Gestão Pública. 58f. Monografia apresentada para o Curso de Pós Graduação em Construção de Obras Públicas da Universidade Federal do Paraná. Curitiba. 2015.

LEÃO, R.H. Caracterização de Incidências Patológicas de um Conjunto Habitacional do Município de Engenheiro Beltrão - Paraná. 39f. Trabalho de Conclusão de Curso de Engenharia Civil, UTFPR, Campo Mourão,2012.

MAGALHÃES, E. F. Fissuras em Alvenaria: ConFigurações Típicas e Levantamento de Incidências no Estado do Rio Grande do Sul. 2004. 177f. Trabalho de Conclusão (Mestrado em Engenharia) - Curso de Mestrado Profissionalizante em Engenharia, Escola de Engenharia/UFRGR, Porto Alegre, 2006.

MATOS, D. BARTKIW, I. N. Introdução ao Mercado Imobiliário. Publicado por Rede ETec. 2013. Disponível em: https://assis.ifpr.edu.br/wpcontent/uploads/2014/11/Introdu\%C3\%A7\%C3\%A3o-aoMercado-Imobili\%C3\%A1rio.pdf

MATTA, T. A. Avaliação do Valor de Imóveis por Análise de Regressão: um estudo de Caso para a Cidade de Juiz de Fora. 43f. Monografia para Graduação em Engenharia de Produção, Juiz de Fora, 2007.

MOREIRA, D. S. Et al. Engenharia de Avaliações de Imóveis apoiada em Técnicas de Análise Multicritério e Redes Neurais Artificiais. Publicado pela Revista de Sistemas de Informação da FSMA n 6 (2010) pp. $49-58$. 
OLIVEIRA, D. F. Levantamento de Causas de Patologias na Construção Civil. Projeto de Graduação apresentado ao Curso de Engenharia Civil, UFRJ/Escola Politecnica. Rio de Janeiro, 2013.

SOUZA, F. B. ANTUNES, G. P. Avaliação de Imóveis: histórico-Cultural x Urbano. 53f. Trabalho de Conclusão de Curso de Engenharia Civil, Universidade do Sul de Santa Catarina, Tubarão, 2017.

TORRES, A. S. e SILVA, J. N. Patologias nos Sistemas Construtivos das Edificações do Inicio do século XX no Rio Grande do Sul - Estudo de Caso de uma Residência na Cidade de Rio Grande/RS. Publicado por REEC - Revista Eletrônica de Engenharia Civil, Vol. 10, setembro de 2015.

VAlente, A. P. V. et al. Análises dos Processos de Recuperação de Patologias: Trincas e Impermeabilizações. Publicado em Construindo, Belo Horizonte, V.1, n.2, p.7, jul/dez. 2009.

ZUCHETTI,P.A.Z. Patologias da Construção Civil: Investigação Patológica em um Edifício Corporativo de Administração Pública no Vale do Taquari/RS. 128f. Trabalho de Conclusão de Curso de Engenharia Civil Centro Universitário Univates, Lajeado, 2015. 